
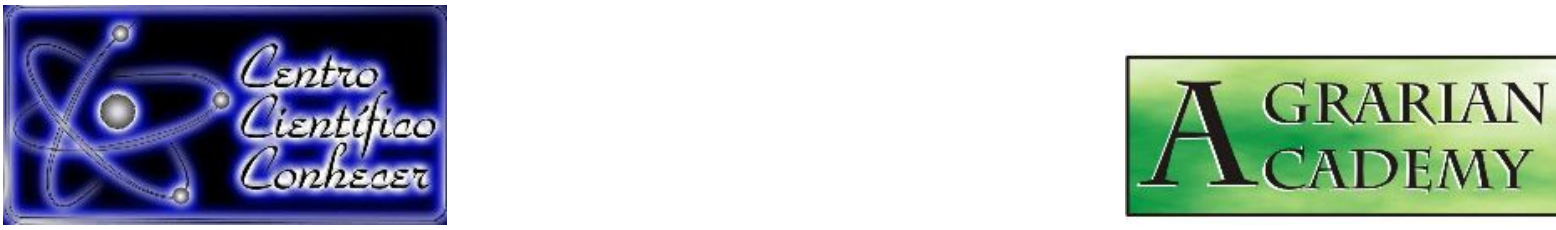

\title{
PROCESSAMENTO DIGITAL DE IMAGENS NA AVALIAÇÃO DA SUPRESSÃO FLORESTAL: ESTUDO DE CASO EM MARCELÂNDIA-MT, NO PERÍODO DE 1986 A 2017
}

Fernando Henrique Alexandre Silva Cerqueira ${ }^{1}$; Ademilso Sampaio de Oliveira ${ }^{2}$; Sylvia Karla Ferreira dos Santos ${ }^{2}$; Wesley Vicentino Claudino ${ }^{2}$, Edgley Pereira da Silva ${ }^{2}$

${ }^{1}$ Engenheiro Florestal (fernandohasc@hotmail.com) Alta Floresta/MT, Brasil

${ }^{2}$ Professor da Faculdade de Ciências Agrárias e Biológicas, UNEMAT, Alta Floresta/MT, Brasil.

Recebido em: 14/07/2018 - Aprovado em: 28/07/2018 - Publicado em: 31/07/2018 DOI: 10.18677/Agrarian_Academy_2018a51

\begin{abstract}
A Amazônia possui uma vasta biodiversidade, é reconhecido pelo mundo todo e está sofrendo constantemente com a exploração de maneira insustentável. No Mato Grosso o desmatamento se iniciou da região sul para o norte chegando ao bioma amazônico. A área estudada é o município de Marcelândia que está localizado na região nordeste do Mato Grosso, com mais de 1.300.000,00 hectares, no qual abriga 145.000,00 hectares de área indígena (Parque Indígena do Xingu). O trabalho propõe-se a analisar a supressão florestal do município de Marcelândia, utilizando imagens orbitais dos satélites LANDSAT e SPOT, no período de 1986 a 2017. O mapeamento da cobertura do solo foi feito por classificação supervisionada pelo método de classificação por Máxima Verossimilhança. Na criação, manipulação e processamento dos dados utilizaram o software ArcGIS 10.1. Através da manipulação dos dados obtiveram a quantidade total de floresta, rios e a área explorada. O inicio da ocupação e exploração do município aconteceu primeiramente na região Sudoeste, onde predomina a presença de relevos aplanados, tendo em seguida a exploração em sentido ao Oeste. Em 1986 o município tinha mais de $90 \%$ de área de floresta, enquanto em 2017 abaixou para $68,81 \%$. Para a área indígena não houve uma perca significante de floresta, perdendo apenas $5.53 \%$ de floresta nativa. Pode-se concluir que a dinâmica de expansão da substituição da floresta apresenta padrão de forte aceleração no período de 1996 a 2008 e de desaceleração no período de 2008 a 2017, para o município inteiro.
\end{abstract}

RESUMO

PALAVRAS-CHAVE: Sensoriamento remoto; Uso do solo e Parque Indígena. 


\title{
DIGITAL PROCESSING OF IMAGES IN THE EVALUATION OF FOREST SUPPRESSION: CASE STUDY IN MARCELÂNDIA-MT, IN THE PERIOD 1986 TO 2017
}

\begin{abstract}
The Amazon has a vast biodiversity, is recognized throughout the world and is constantly suffering from exploitation in an unsustainable way. In Mato Grosso, deforestation started from the south to the north, ending at the end of the Amazon biome. The area studied is the municipality of Marcelândia, which is located in the northeast region of Mato Grosso, with more than 1,300,000.00 hectares, in which it holds 145,000.00 hectares of indigenous area (Xingu Indigenous Park). The work proposes to analyze the forest suppression of the municipality of Marcelândia using orbital images of the LANDSAT and SPOT satellites from 1986 to 2017. The mapping of the ground cover was done by classification supervised by the Maximum Likelihood classification method. In the creation, manipulation and processing of the data, they used the software ArcGIS 10.1. Through the manipulation of the data they obtained the total amount of forest, rivers and the area explored. The beginning of the occupation and exploration of the municipality happened first in the Southwest region, where predominates the presence of flattened reliefs, after which the exploration towards the West. In 1986 the municipality had more than $90 \%$ of forest area, while in 2017 it lowered to $68.81 \%$. For the indigenous area there was not a significant loss of forest, losing only $5.53 \%$ of native forest. It can be concluded that the dynamics of expansion of forest substitution shows a pattern of strong acceleration in the period from 1996 to 2008 and deceleration in the period from 2008 to 2017 for the entire municipality.
\end{abstract}

KEYWORDS: Remote sensing; Land use and Indigenous Park.

\section{INTRODUÇÃO}

O Brasil é um país beneficiado quando se trata de formações florestais, sendo o bioma amazônico o mais destacado e reconhecido pelo mundo todo. De acordo com a organização global GREENPEACE (2017), a floresta amazônica possui mais de 6,9 milhões de $\mathrm{km}^{2}$ e abrange nove países sul-americanos.

As áreas desmatadas no bioma amazônico foram na grande maioria convertidas em atividades agropastoris, o que implica em uma gigante perda de biodiversidade, diminuição da ciclagem da agua, menor taxa de fixação de carbono além de diversos danos ao solo (FEARNSIDE, 2005).

No estado de Mato Grosso que ainda possui uma ampla área de floresta ombrófila aberta, existe uma grande pressão da agricultura sobre a floresta, de forma ascendente do sul para o norte do estado. Anteriormente se tinha um grande avanço somente sobre a floresta, porém hoje a agricultura vem tão forte que afeta até a pecuária no estado, tendo uma nova conversão de pastos em lavouras.

Uma forma de estudar e analisar estes impactos são por meio das Geotecnologias. Segundo Pons e Pereira (2018) a utilização do geoprocessamento integrando diversas informações, como as imagens de superfície, relevos e distribuição hidrográfica proporcionam dados devidamente confiáveis, onde é possível diagnosticar e monitorar as mudanças na paisagem natural, através de informações periódicas de alvos desejáveis, contendo alta precisão e baixo custo.

A utilização dos sensores TM e ETM+ da serie LANDSAT para análises de desmatamento é eficiente, através da composição de bandas RGB se consegue uma imagem em cores verdadeiras podendo assim se fazer diferenciações de 
pastagens e floresta. Essas imagens possuem pixel de 30 metros quadrados podendo chegar á 15 metros quadrados quando feita a junção à banda pancromática $(E T M+)$, o que é uma resolução espacial conveniente por se tratar de dados gratuitos (SOARES, et al., 2015).

O município de Marcelândia-MT conta com mais de 1,3 milhões de hectares, e sofre com a exploração e conversão florestal (IBGE, 2016), onde predomina presença de floresta ombrófila aberta. Emancipada desde 1986, pela Lei ํㅜ. 4992, a cidade vem aumentando as áreas exploradas a cada dia, e por possuir um grande potencial madeireiro, a exploração florestal se tornou sua base econômica. Com a crise madeireira e o aumento da fiscalização por meados de 2008, houve um decréscimo na produção, abrindo novas portas para outras atividades como agricultura e pecuária.

O trabalho possibilita gerar informações que poderão ser utilizadas como instrumentos de política, planejamento e gestão ambiental do município, facultando também a utilização dos dados disponibilizados pelo SIG, para a pesquisa e desenvolvimento de projetos nas mais diversas aplicações do Geoprocessamento e das Ciências Florestais, por parte da comunidade acadêmica, científica e pela população em geral, considerando que não existem ainda tais informações produzidas. Por fim, o presente trabalho visa analisar a supressão florestal do município de Marcelândia- MT, utilizando imagens orbitais dos satélites LANDSAT e SPOT, no período de 1986 - 2017.

\section{Localização da área de estudo}

\section{MATERIAIS E MÉTODOS}

O Município de Marcelândia (Figura 1) está localizado no norte do estado de Mato Grosso, aproximadamente setecentos quilômetros da capital Cuiabá. A cidade teve inicio a partir de um projeto de colonização (Colonizadora Maiká), e se tornou um município efetivo pela Lei no 4992 em 13 de maio de 1986. O município possui uma área de 1.320.000 hectares, possuindo em seu interior 145.000 hectares de área indígena (parque do Xingu), que correspondem á aproximadamente $13 \%$ da área do município (IBGE, 2016).

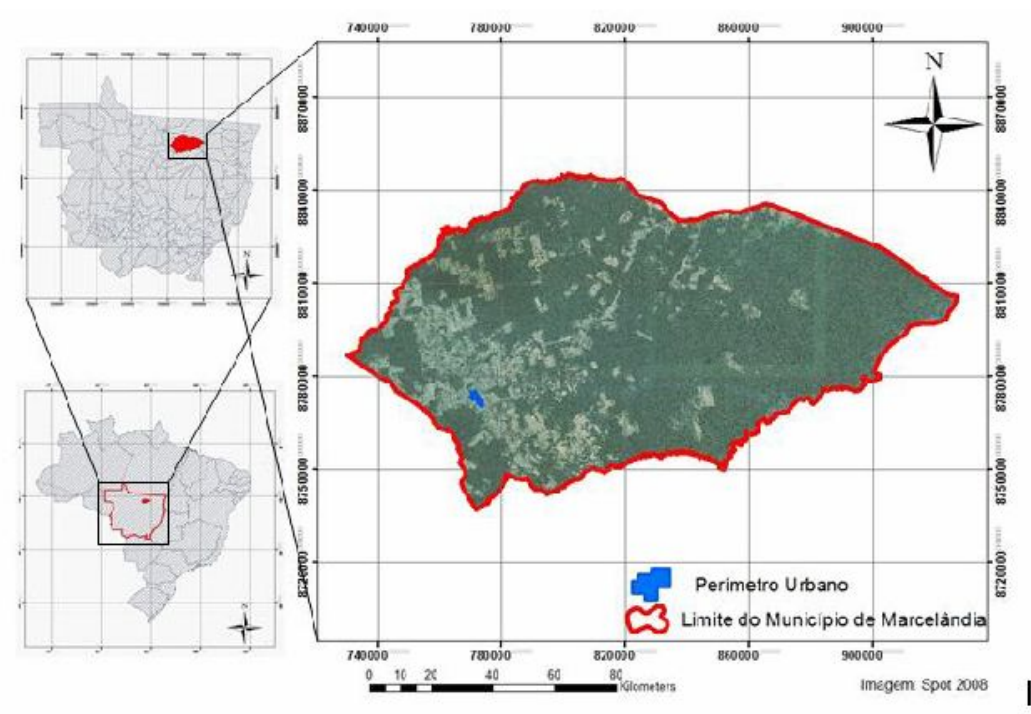

FIGURA 1 - Mapa de localização da área de estudo, em destaque o município de Marcelândia - MT 


\section{Materiais Utilizados}

Neste estudo foram utilizadas imagens orbitais dos satélites LANDSAT 5 para os anos de 1986 e 1996, SPOT para o ano de 2008 e LANDSAT 8 para 2017, obtidas pelo site do INPE e processadas por técnicas de geoprocessamento na produção de informações sobre o uso e ocupação dos solos. Foi realizada uma análise quantitativa das áreas em expansão e um diagnóstico dos diferentes tipos de usos do solo. Todas as imagens utilizadas foram obtidas entre os meses de maio a outubro, essas datas foram escolhidas por fornecer melhor qualidade de imagem sem registro de nuvens.

\section{Processamento de Imagem de Satélite}

O município de Marcelândia-MT, possui um extenso limite, então foram necessárias 4 cenas diferentes para cada ano, para produzir o mosaico completo do município para as imagens LANDSAT. Para o ano de 2008 o mosaico foi criado utilizando 9 cenas, já que foi utilizado imagens SPOT-5 com maior resolução espacial.

Produziu-se então uma classificação da imagem do sensor TM-Landsat-5 e OLI-Landasat-8, com resolução espacial de $30 \mathrm{~m}$, e $15 \mathrm{~m}$ respectivamente e Satélite SPOT-5 HRG - (High Resolution Geometric) de $2.5 \mathrm{~m}$. Para obter as áreas de expansão agrícola do município foi realizada uma classificação supervisionada do algoritmo de máxima verossimilhança-Maxver e foram obtidas as classes e interpretadas como (1) Floresta, (2) Área Explorada e (3) Rios.

A manipulação das imagens foi realizada no software Arcgis 10.1 (versão demonstrativa), onde as operações de processamento foram realizadas, tais como: classificações, cruzamentos e análises espaciais, visando à edição de um mapa.

\section{RESULTADOS E DISCUSSÕES \\ Potencial e Distribuição dos Recursos Hídricos}

O município de Marcelândia-MT possui uma imensa rede hidrográfica, contando com quase $6.300 \mathrm{~km}$ em extensões de rios, incluindo os permanentes, intermitentes e efêmeros. Segundo Nora (2012) as redes fluviais do Mato Grosso são de extrema importância e abastecem as três maiores bacias hidrográficas do Brasil, que são: a bacia Amazônica, a bacia Platina e a bacia do Araguaia-Tocantins. As redes hidrográficas do município abastecem na maior parte a Bacia do Araguaia - Tocantins, através dos principais rios da cidade representados na figura 2, 0 Manissauá-miçu (popularmente conhecido como Manito), e rio Peixoto de Azevedo, ambos desaguando no rio Xingu.

Os rios do Mato Grosso em geral vêm sofrendo forte degradação ambiental, por parte de atividades agrícolas. No município inicialmente as áreas de floresta eram derrubadas para atividades pecuaristas, e os rios eram utilizados como fonte de água para a dessedentação animal. Atualmente grande parte do município está adotando as lavouras como prática agrícola, assim utilizando as águas para a irrigação. O ponto negativo é que as atividades de lavoura necessitam de insumos agrícolas, que por sua vez, voltam para os rios através do escoamento superficial e percolação no solo, influenciando diretamente na qualidade da agua e na sua biodiversidade.

De acordo com o Código Florestal Brasileiro (CFB) as Áreas de Preservação Permanente (APP's) possuem a função ambiental de preservar os recursos hídricos, a paisagem, a estabilidade geológica e a biodiversidade, além de facilitar o fluxo gênico de fauna e flora. Segundo Guimarães et al. (2015), a vegetação presente nas 
faixas marginais dos rios, obstruem o escoamento superficial, favorecendo a infiltração e diminuindo o risco de erosão no local. As APP's, ainda influenciam no combate às alterações climáticas em diferentes escalas de abrangência, a preservação do patrimônio genético, não só por garantirem a sobrevivência de inúmeras espécies de fauna e flora, mas também funcionando como um corredor ecológico para o fluxo gênico entre as unidades de conservação e as áreas de Reserva Legal, e ainda a manutenção da fertilidade e estabilidade dos solos.

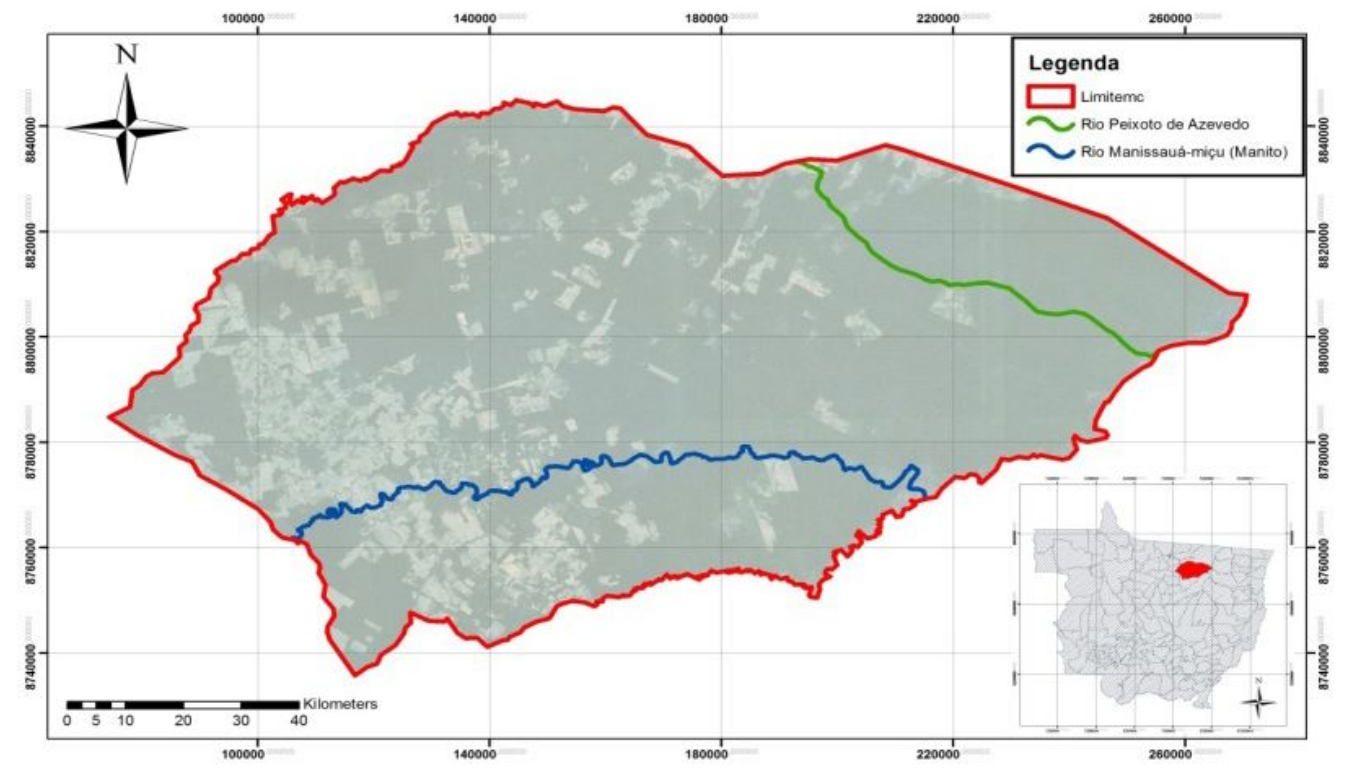

FIGURA 2 - Principais malhas hidrográficas do município de Marcelândia-MT

A extensa malha hídrica do município demonstra a característica de biomas amazônicos, com 1259 nascentes contabilizadas de acordo com bases cartográficas da SEMA, que podem ser visualizadas na figura 3, tendo em Marcelândia pelo menos cinco metros de rio por hectare do município e uma nascente a cada mil hectares.

Com tamanha disponibilidade hídrica, Marcelândia possui um papel importante na preservação dos recursos hídricos, por que abriga em seus limites territoriais as principais nascentes dos rios que compõem a bacia hidrográfica do Araguaia - Tocantins.

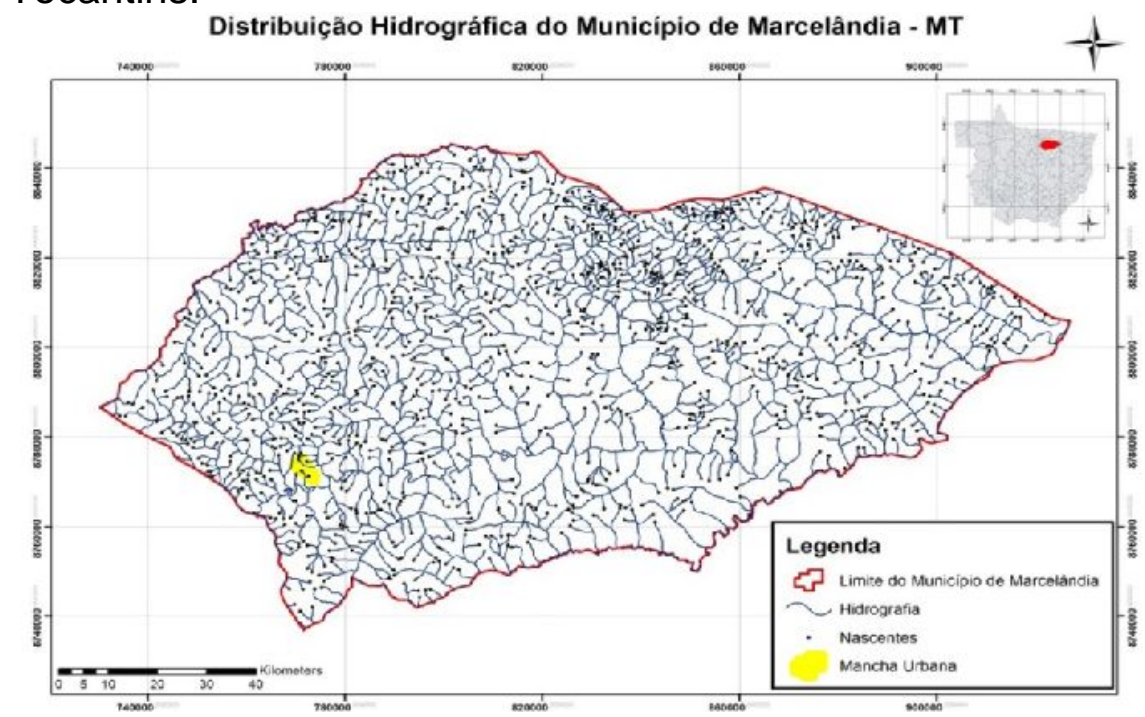

FIGURA 3 - Hidrografia e nascentes do município de Marcelândia-MT 
Ainda sobre o novo Código Florestal Brasileiro, as faixas marginais dos cursos d'água são consideradas como APP's, e para rios com menos de dez metros de leito regular deve se considerar no mínimo trinta metros de APP's para áreas não consolidadas. Para nascentes e olhos d'agua perenes de preservação permanente deve possuir um raio mínimo de 50 metros para áreas não consolidadas. Considerando esses dados, para o município de Marcelândia, teria que ter no mínimo 25.195 hectares de APP's considerando os rios e nascentes que são os tipos de áreas de preservação mais influentes no município.

\section{Características Fisiográficas do Município}

Os relevos são irregularidades na superfície da terra, que representam o reflexo das atividades sísmicas juntamente com o intemperismo, resultando em diversos tipos de relevos. Segundo Paradella et al. (2003), os dados de relevos de uma determinada região são de extrema importância para análises ambientais geoespaciais, tendo diversas aplicações em áreas abrangentes.

No município de Marcelândia-MT a altimetria é variada desde $84 \mathrm{~m}$ até $523 \mathrm{~m}$ de altitude, possuindo na parte norte o ponto mais alto (constituindo relevo ondulado a forte ondulado) e em segmentação aos principais rios (Manito e Peixoto de Azevedo) as partes mais baixas (relevo plano e suave ondulado).

Fazendo a comparação dos mapas altimétrico (figura 4) e hidrográfico (figura 3 ), pode se observar que na porção norte próximo ao pico concentra-se a maior quantidade de nascentes. Nota-se que as áreas de exploração estão evidentemente nos pontos mais baixos de menos variação altimétrica (relevos aplanados).

Até 2005 , mais de $23.5 \%$ do município que foi explorado, foram áreas de relevo aplanado, correspondentes a mais de $265.000,00$ ha, comprovando que esses são os tipos de formações preferida dos exploradores para nas diversas atividades agrícolas na região.

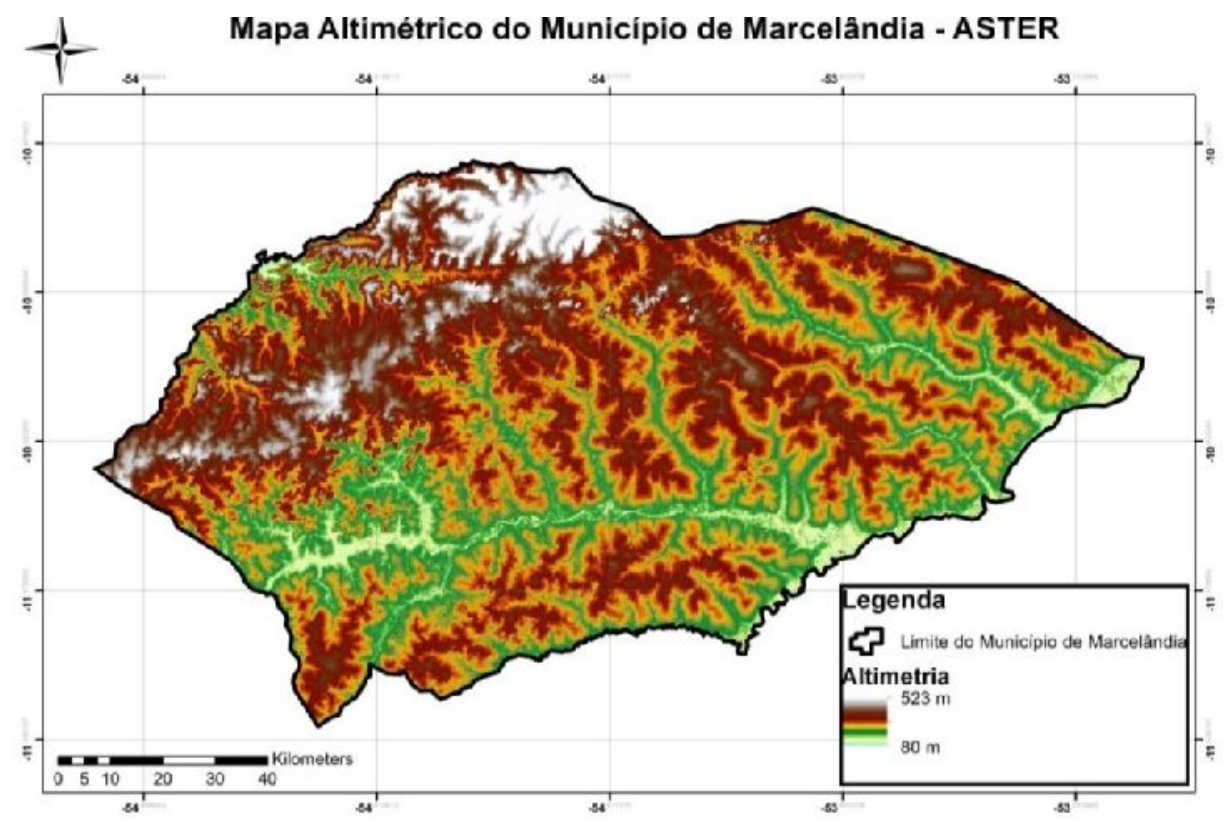

FIGURA 4 - Altimetria do município de Marcelândia-MT

\section{Uso e ocupação dos solos}

Em 1986 quando Marcelândia deixou de ser distrito de Sinop - MT, já havia uma parte considerável de área explorada. Segundo relatos de pioneiros do 
município, a extração madeireira era realizada sem algum tipo de supervisão técnica e/ou fiscalizações, eram retiradas as madeiras de maior valor comercial e as outras descartadas sem algum tipo de manejo. É possível visualizar na figura 4 que a maior área explorada no ano de 1986 esta localizada na região Sudoeste, que era e é até hoje a principal forma de acesso á cidade, através da MT-320 que está ligada á BR163. Além do contato com a estrada, deve se considerar que, onde houve os primeiros tipos de exploração no município foram nas regiões de relevo Aplanado, tipos de relevos indicados para práticas agrícolas.

No ano de 1986, há um total de 1.320.000,00 ha, sendo que dentro desta área foi classificado o equivalente a $1.198 .447,50$ ha de floresta nativa, o que equivale a $90,79 \%$ da área, um total de $23.338,62$ ha de rios que corresponde a $1,77 \%$ e um total de $98.213,88$ ha de área desmatada que corresponde a $7,44 \%$.

Através de relatos e da interpretação visual das imagens LANDSAT 5 de 1986 é possível observar algumas áreas abertas para a implantação da pecuária e algumas manchas de área explorada no interior da floresta confirmando a exploração florestal. As lavouras eram adotadas apenas em pequena escala, sem mecanização e/ou tecnologias como a utilização de insumos agrícolas, causando danos mínimos ao solo, rios e biodiversidade do local.

De acordo com Soares-Filho et al. (2005), existem diversas causas que explicam o desmatamento, geralmente são causas inter-relacionadas, que compreendem desde incentivos fiscais e politicas de colonização passadas que estimularam a migração para a Amazônia, provocando o avanço da exploração madeireira, a pecuária e posteriormente o agronegócio. No princípio das ocupações no Mato Grosso as explorações eram de baixa escala, considerando a tecnologia da época, era praticada apenas uma agricultura de subsistência (ANDERSON et al., 2003).

Em 1996, 10 anos após a origem do município aumentou de forma considerável as áreas exploradas na região sudoeste, tendo algumas áreas exploradas também na região norte em sentido á região leste. Na figura 6 em 1996 já é possível observar diversas propriedades abertas próximas a zona urbana e também o surgimento de estradas ligando a região leste do município. Pode-se observar também, que o desmatamento do município segue para as regiões de relevo Aplanado, evidenciando o interesse dos exploradores por esse tipo de solo.

As atividades agrícolas evidenciadas a partir da interpretação visual, ainda demonstram na maioria como a de pecuária e algumas de garimpo na região norte que faz divisa com Peixoto de Azevedo, considerado um dos municípios mais ativos na prática do garimpo no Mato Grosso. A lavoura ainda não possuía área considerável, sendo ainda empregada por agricultores familiares. Segundo Batalha (2005) o processo de implantação da lavoura em uma região tem princípio nos pequenos produtores, que indicam a aptidão agrícola de certo local, mesmo que com pouca tecnologia, atraindo posteriormente os grandes produtores.

No ano de 1996 a área que compreende a floresta, diminuiu 5,25\% em relação ao ano de 1986, e teve como principal motivo o avanço das áreas de pastagens de forma pouco planejada na abertura de novas áreas (áreas exploradas), que possuem um aumento de $4,86 \%$ quase o dobro do valor que teve em 1986. Os rios tiveram um aumento de $0,39 \%$, que é significativo considerando o tamanho do município, esse aumento pode ser explicado pelo desmatamento marginal dos rios, realizado pelos pecuaristas para que o gado possa chegar até o leito do rio. 


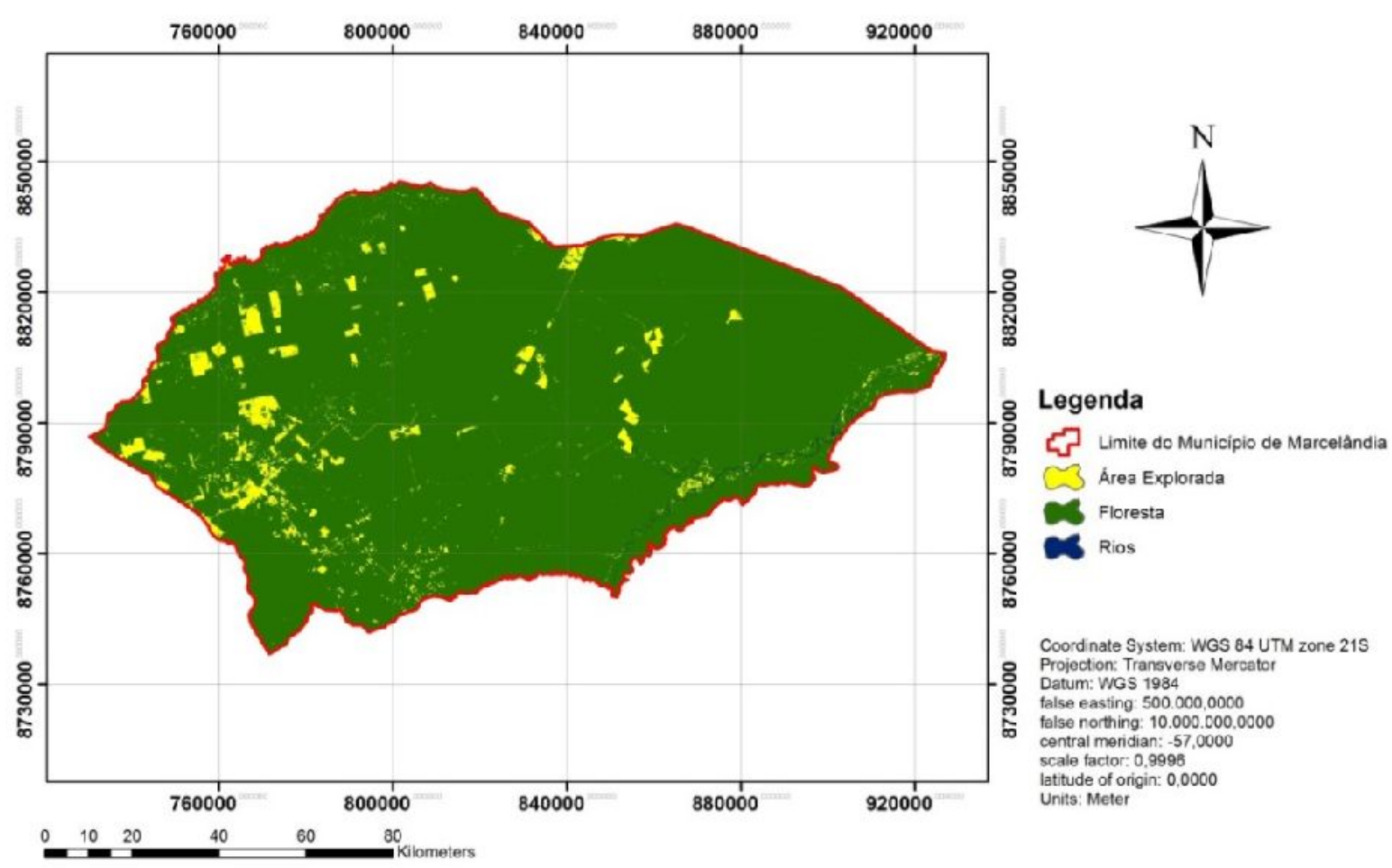

FIGURA 5 - Mapa de Cobertura vegetal do Município de Marcelândia-MT $-1986$

Em 1996 o mapa de Uso e Ocupação demonstrou que 1.129.132,27 ha foram classificados como área de floresta nativa, o que equivale a $85,54 \%$ da área, um total de $28.492,24$ ha de rios que corresponde a $2,16 \%$ e um total de $162.375,49$ ha de área desmatada que equivalente a 12,30\%.

Para o ano de 2008 foram utilizadas imagens SPOT de $2,5 \mathrm{~m}$ de resolução espacial, é possível obter uma imagem mais detalhada, possibilitando analisar que após 22 anos de município, as áreas exploradas se concentraram na parte sudeste (predominância do relevo aplanado) na maioria, com muitos pontos explorados nas partes de floresta, indicando possíveis formas de manejo florestal, como pode ser observado na figura 7.

Nesse ano as lavouras começaram a ingressar na ocupação de solo do município, adotando áreas de pastagens que já estavam abertas e de certa forma fazendo com que algumas novas áreas fossem abertas. Para este ano a quantidade de floresta diminuiu 12,87\%, mais que toda área explorada acumulada até 1996. Em reflexo á esta área explorada os rios aumentaram 1,64\%, indicando que ainda havia exploração em áreas marginais aos rios, causando assoreamento e aumentando os espelhos d'água. Segundo Silva et al. (2017) a retirada da vegetação natural reduz de forma direta a biodiversidade do local, leva a formação de ilhas (fragmentação da vegetação), que são passivas do efeito de borda. 


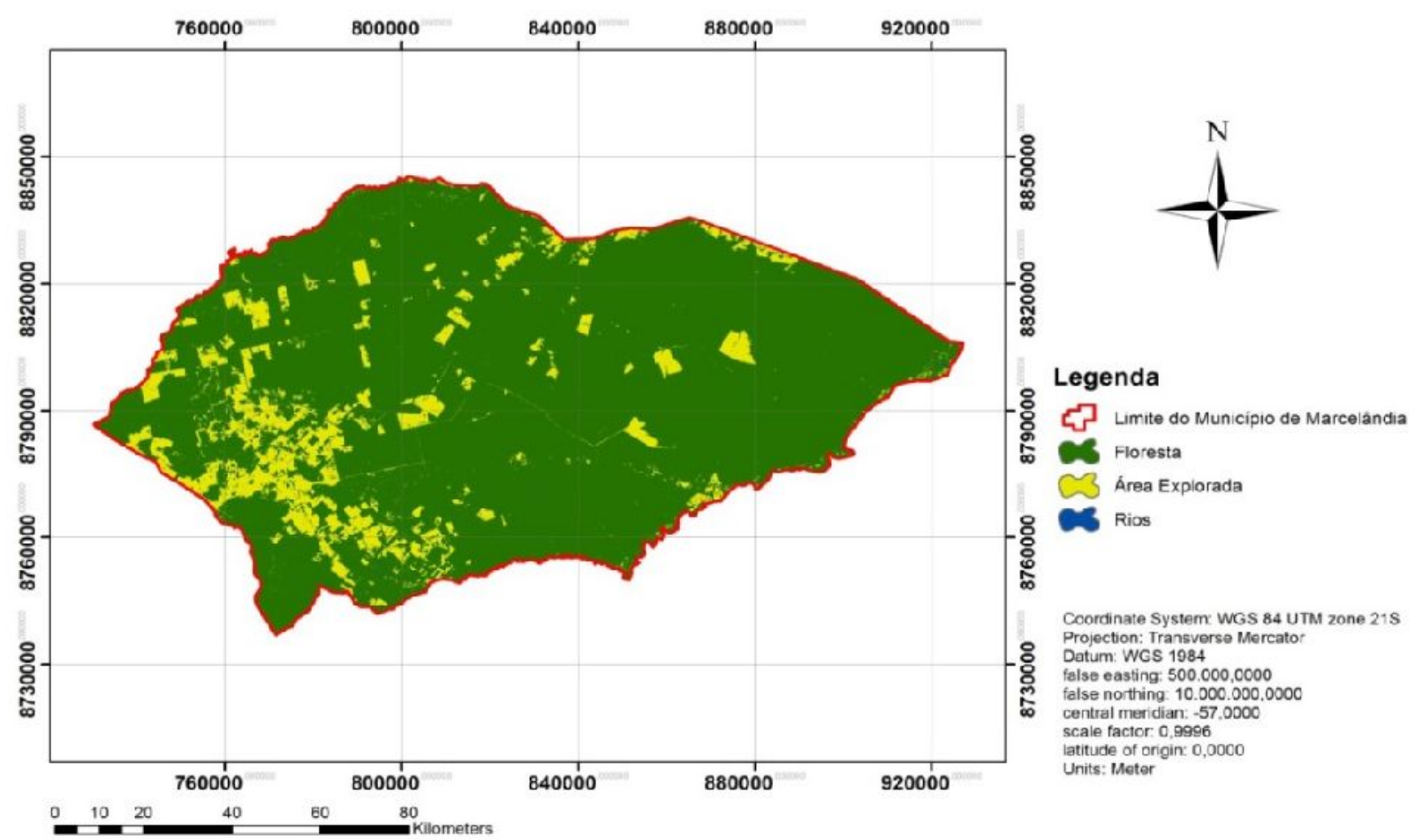

FIGURA 6 - Mapa de Cobertura vegetal do Município de Marcelândia-MT1996

No mapa de Uso e Ocupação de 2008, observou-se que o desmatamento estava crescendo descontroladamente, com a fiscalização precária, o mercado madeireiro ilegal do município estava em alta. Em 2008 foram contabilizados 959.253,38 ha de floresta nativa, o que equivale a $72,67 \%$ da área, um total de $50.217,47$ ha de rios que corresponde a 3,80\% e um total de $310.529,15$ ha de área desmatada que corresponde a $23,52 \%$.
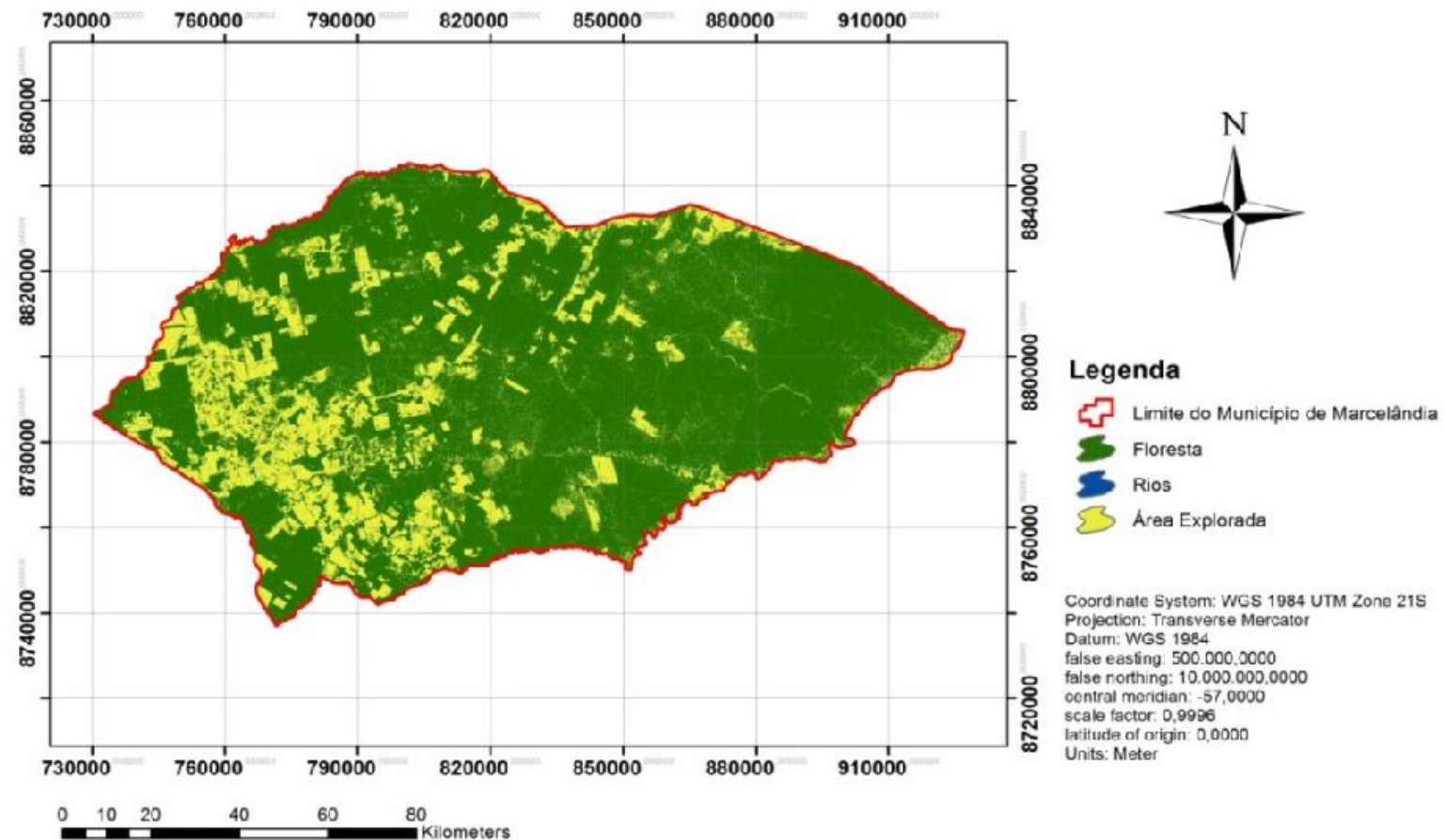

FIGURA 7 - Mapa de Cobertura vegetal do Município de Marcelândia/MT - 2008 
No ano de 2017, após 31 anos de consolidação do município, nota-se que ainda houve um aumento na área explorada, porém pode-se observar que há menos pontos de exploração na floresta, indicando que houve algum tipo de regeneração da mesma. Segundo Fragoso et al. (2016) a regeneração natural depende diretamente de condições ambientais favoráveis, para promover a formação, dispersão, germinação e vigoramento das plantas. A regeneração natural é fundamental para a restauração de novas áreas, pois ela ajuda no processo de renovação da composição florística e a manutenção das espécies nativas, de fauna e flora de um determinado local.

$\mathrm{O}$ ano de 2008 foi destacado por ser a data em que foi assinado o Decreto $\mathrm{n}^{\circ}$ 6.514 de julho de 2008, que dispõe sobre as infrações e sanções administrativas ao meio ambiente, estabelece o processo administrativo federal para apuração destas infrações, além de trazer, em seção própria, as infrações administrativas cometidas contra o meio ambiente, respeitando as sanções e valores de multa previstos na Lei $n^{\circ} 9.605 / 98$, ou seja, punindo os infratores ambientais.

As áreas classificadas como florestas tiveram uma queda de $12,87 \%$ enquanto os rios diminuíram $0,06 \%$, que é muito considerável, o que indica que houve desmate, nas Áreas de Preservação Permanentes não foram danificadas. Isso pode ser mais um reflexo da presença de lavoreiros, que preferem manter, proteger e restaurar as APP's nas margens dos rios e nascentes, desempenhando o papel de proteger os recursos hídricos, para posteriormente poder desfrutar dos mesmos, enquanto os pecuaristas utilizam as margens dos rios e acabam prejudicando o solo e a qualidade da água. Aos poucos os processos de ocupação foram mudando, e a agricultura apresenta uma serie de fatores de pressão sobre a pecuária, além da imensidão de recursos governamentais a agricultura trás um enorme retorno financeiro, e ajuda a manter o equilíbrio em Áreas de Preservação Permanente.

Em 2017 houve a menor quantidade de floresta com apenas $908.319,46$ ha, representando $68,81 \%$ do município. A extensão da área explorada também atingiu o maior valor nos anos estudados, chegando a $362.248,66$ ha, expressando $27,44 \%$ e os rios tiveram uma redução comparada á 2008 com 3,74\% da área total do município, representados na figura 8.

Segundo Wollmann e Bastos et al. (2014) a Reserva Legal é uma área designada a assegurar o uso econômico de modo sustentável dos recursos naturais de um imóvel rural, além de abrigar a fauna silvestre, proteger a flora nativa e promover a conservação e a reabilitação dos processos ecológicos. 


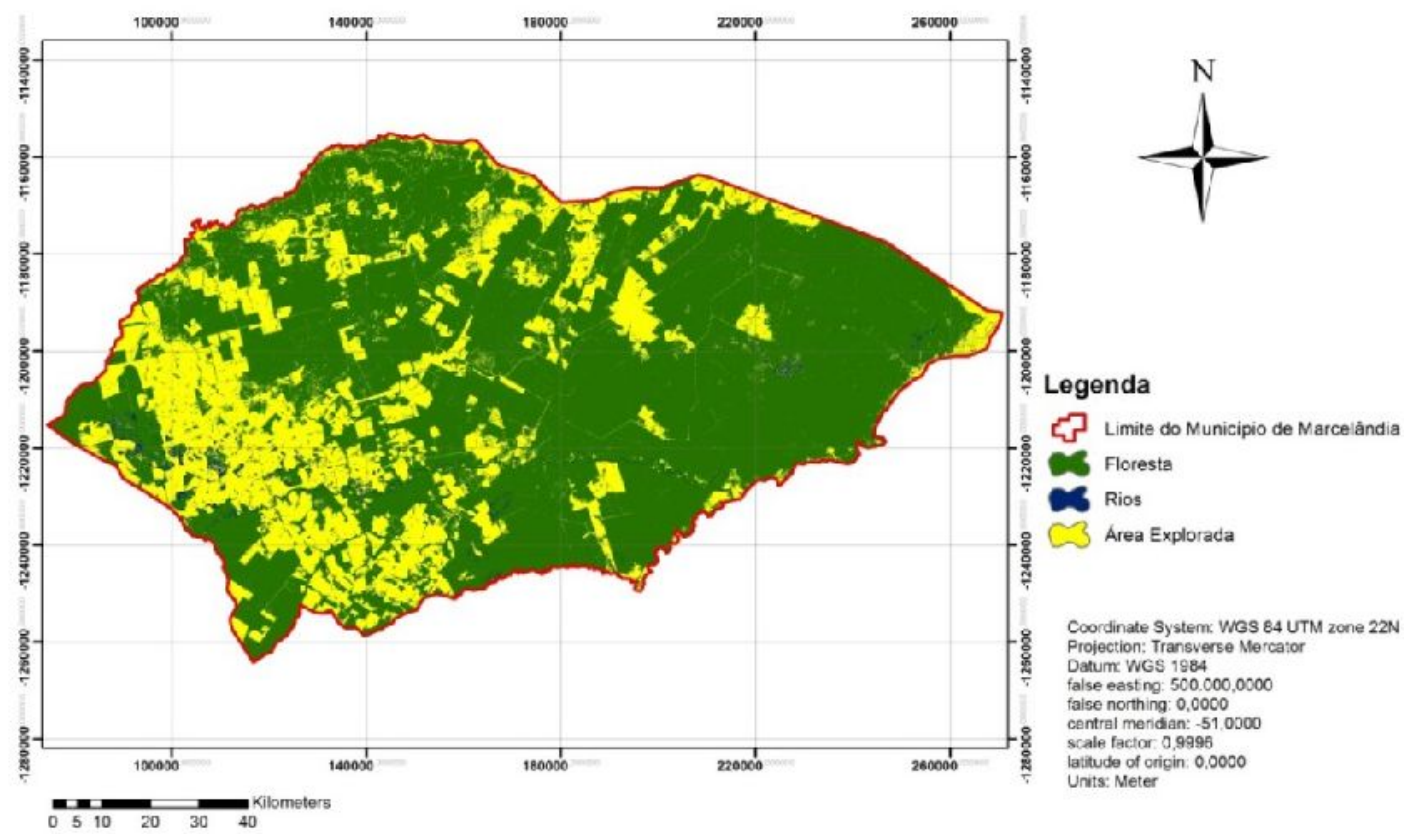

FIGURA 8 - Mapa de Cobertura vegetal do Município Marcelândia/MT- 2017

Através da figura 9, pode se observar que de 1996 para 2008 houve o maior aumento de área explorada e que até 1996 o município ainda possuía mais de $80 \%$ de floresta como está regido no Código Florestal. Ainda pode-se notar que de 2008 a 2017 foram os únicos anos em que ocorreu certo equilíbrio no avanço da ação antrópica sobre a floresta.

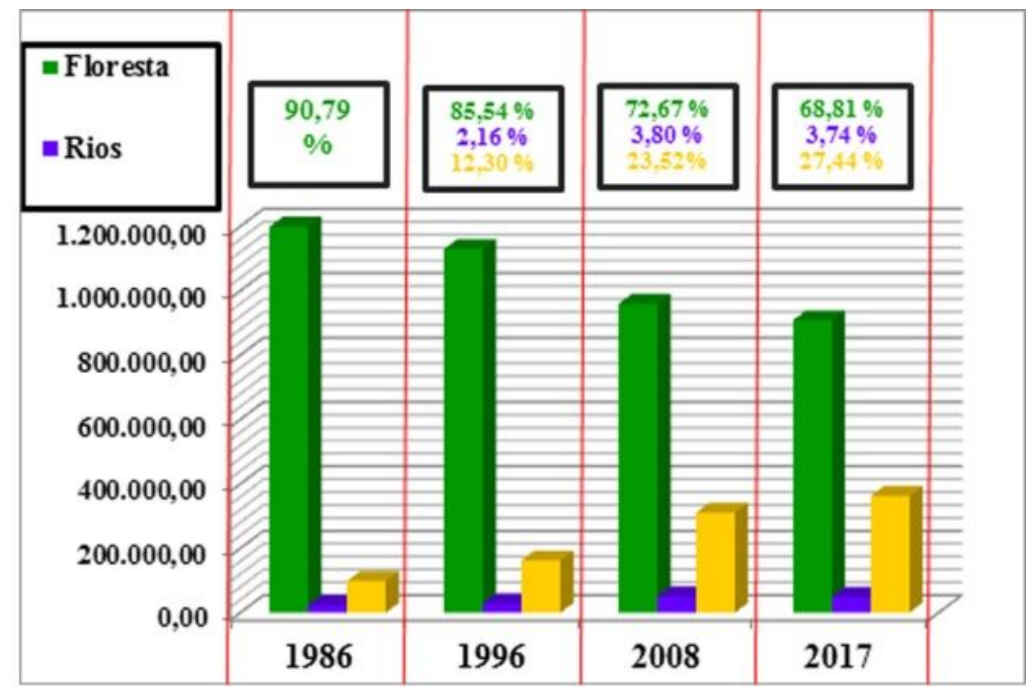

FIGURA 9 - Gráfico da quantificação de Florestas, Rios e Área Explorada para cada ano em estudo.

Uma das formas encontradas pelo poder público para promover a preservação dos ecossistemas amazônicos foi a criação de unidades de conservação, onde se restringe ou se controla a exploração de recursos. Segundo Romero e Leite (2014) os parques indígenas são chamados unidades de uso indireto, onde a exploração de recursos naturais é estritamente proibida. No município o parque do Xingu representa quase 13\% do território total. 
A área indígena ocorrente no município está localizada na região leste, seguindo o afluente rio Xingu. Na data inicial dos estudos regidos por este trabalho, em 1986, a região do parque indígena já era uma Unidade de Conservação, e pode ser visualizado através da figura 10, que não há áreas consideráveis exploradas, apenas algumas partes do rio que durante a seca ficam expostos, formando dunas de areia no meio e nas laterais dos rios, sendo então, interpretados pelo classificador como uma área explorada.

No ano de 1986 na área indígena, há um total de 145.000 ha, sendo que dentro desta área foi classificado o equivalente a $141.132,10$ ha de floresta nativa, o que equivale a $97,33 \%$ da área, um total de 1.119,94 ha de rios que corresponde a $0,77 \%$ e um total de $2.747,96$ ha de área desmatada que corresponde a $1,90 \%$.

Para o ano de 1996 já é possível observar alguns pontos de exploração no interior da floresta, indicando que houve algum tipo de exploração ilegal na área Indígena. $\mathrm{Na}$ classificação realizada não foram consideradas algumas dunas de areia expostas próximas aos rios, que diminuíram os valores de áreas exploradas. Ainda é possível observar que diminuíram os valores de espelhos d'água quando comparados com o ano de 1986.

Em 1996 a área indígena demonstrou que 142.666,44 ha foram classificados como área de floresta nativa, o que equivale a $98,39 \%$ da área, um total de 608,02 ha de rios que corresponde a $0,42 \%$ e um total de $1.725,54$ ha de área desmatada que equivalente a $1,19 \%$.

Em 2008 com a utilização de imagens SPOT, é possível identificar, de acordo com a figura 12, diversas áreas classificadas como exploradas, principalmente acompanhando os principais rios da área indígena. As áreas exploradas aumentaram 7,26 \%, aumentando também os espelhos d'água em 1,40\%. Deve-se ressaltar que as comunidades indígenas são dependentes dos rios, e geralmente vivem próximos a eles, podendo ser um dos agentes causadores de exploração, mesmo que de baixo impacto.

Para este ano de estudo, foram contabilizados como floresta $130.098,35$ ha, ou $89,72 \%$, para os rios tiveram $2.644,01$ ha correspondentes á $1,82 \%$ e para as áreas exploradas $12.257,64$ ha de extensão, representando $8,45 \%$ do município.

Para o último ano em estudo é possível observar no mapa de cobertura vegetal, que na parte nordeste do município há uma parte totalmente degradada, indicando através da interpretação visual que houve exploração nas áreas marginais do rio Xingu. O classificador também considerou dois pontos na floresta como rios, que é a representação de duas áreas de mata aluvial.

Em 2017 houve um aumento na quantidade de floresta com 133.110,14 ha, representando $91,80 \%$ do município. A extensão da área explorada diminuiu, considerando o ano de 2008 abaixando para $9.308,75$ ha, expressando $6,42 \%$ e os rios tiveram uma redução com $1,78 \%$ da área total do município.

A unidade de conservação pode ser considerada protegida, já que não houve em nenhum dos anos estudados, valores alarmantes de exploração, como demonstrados na figura 11. Após 2008 onde teve a maior quantidade de área explorada houve um aumento nas áreas de floresta, demonstrando que teve regeneração natural da mata. 

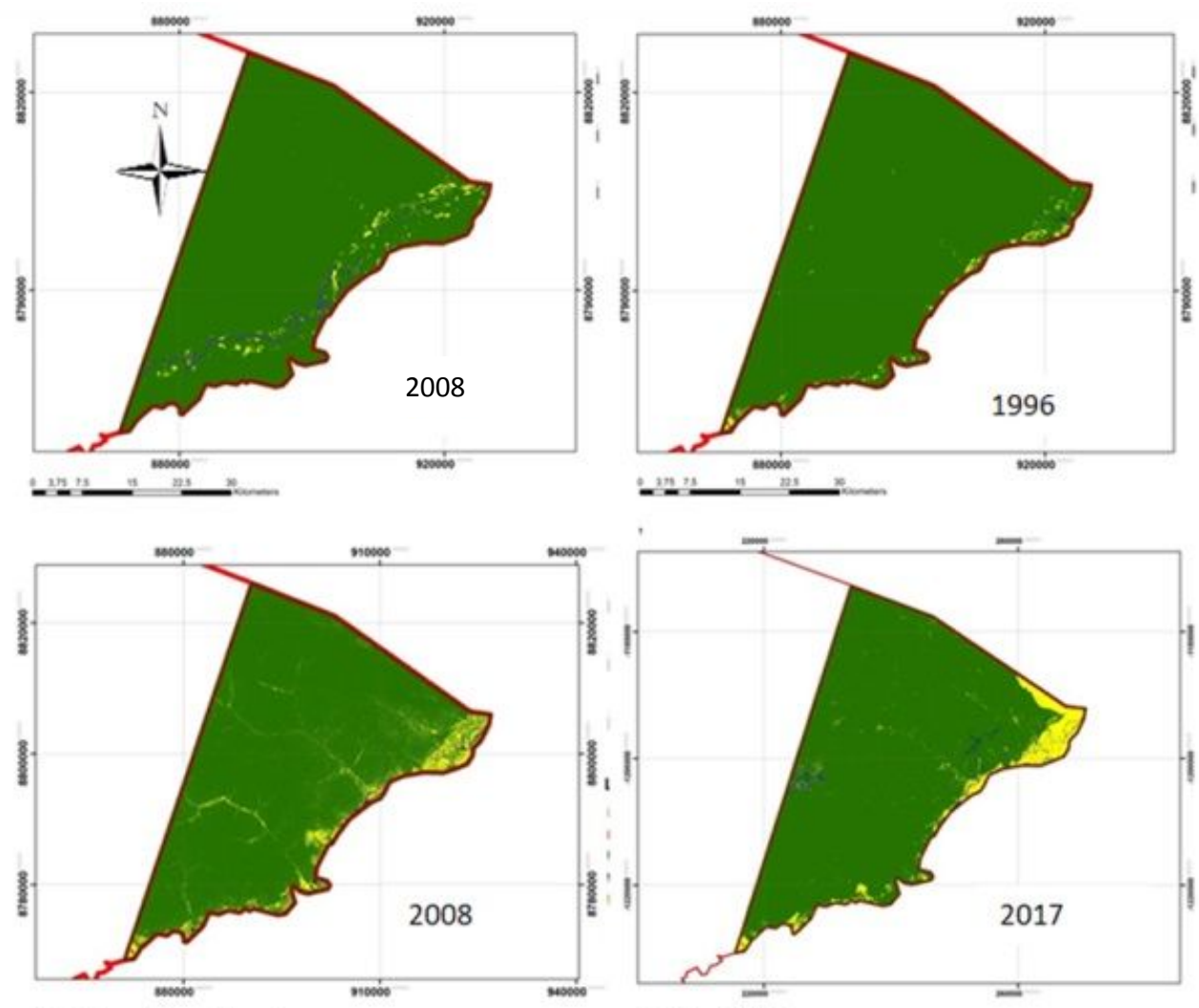

\section{Legenda}

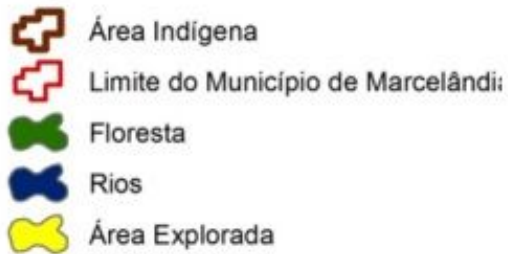

FIGURA 10 - Mapa de Cobertura Vegetal da Área Indígena para o ano de 1986 a 2017.

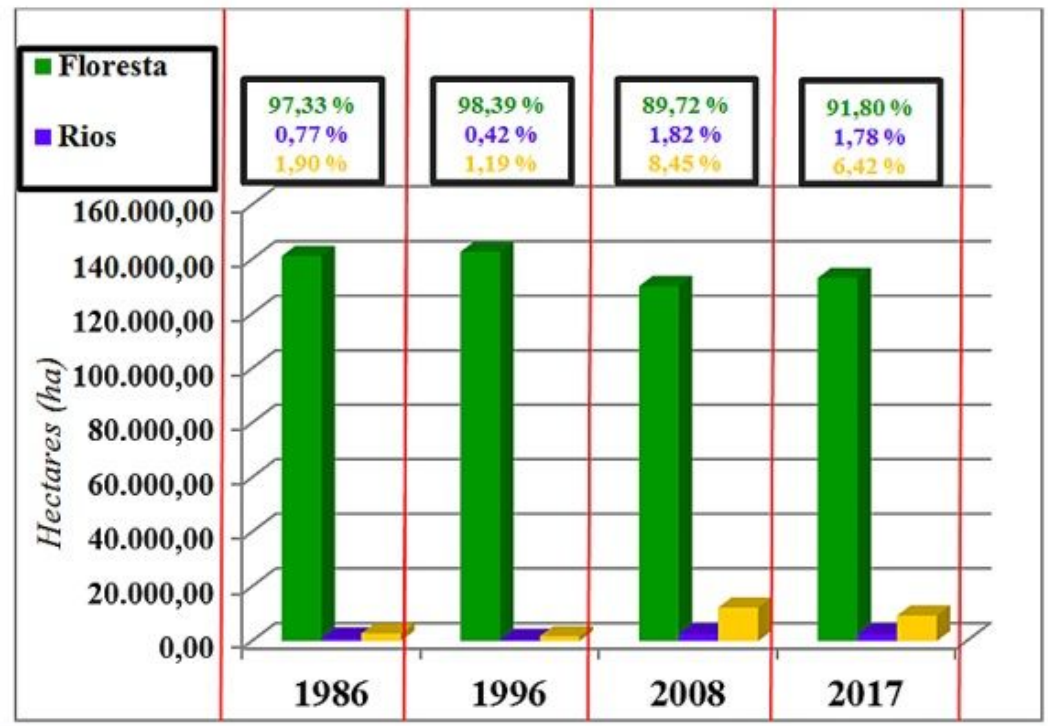

FIGURA 11 - Quantificação da Cobertura vegetal, Rios e Área Explorada para cada ano em estudo na Área Indígena AGRARIAN ACADEMY, Centro Científico Conhecer - Goiânia, v.5, n.9; p.532 2018 


\section{CONCLUSÃO}

Os dados evidenciam que inicialmente é feita a exploração madeireira do local, e depois ocorre a substituição da cobertura vegetal original para a implantação das atividades agrícolas como a instalação de pastagens e lavouras.

A dinâmica de expansão da substituição da floresta apresenta padrão de forte aceleração no período de 1996 a 2008 e de desaceleração no período de 2008 a 2017, para o município inteiro.

A área desmatada de 2017 foi a maior entre todos os outros anos anteriores, chegando á 362.248,66 ha de área explorada, ou seja, 27,44\% do município.

O município conseguiu manter sua área indígena protegida, tendo apenas em 2008 o maior pico de exploração, que foi ordenado no ano de 2017.

\section{REFERÊNCIAS}

ANDERSON, L.O.; ROJAS, E. H. M.; SHIMABUKURO, Y. E. Avanço da Soja Sobre os Scossistemas Cerrado e Floresta no Estado do Mato Grosso. Anais XI SBSR, Belo Horizonte, Brasil, INPE, p. 19-25, abril 2003. Disponível em: < http://marte.sid.inpe.br/attachment.cgi/ltid.inpe.br/sbsr/2002/11.17.12.25/doc/01_304. pdf> Acesso em: 14 mai. 2018.

BATALHA, M.O.; BUAINAIN, A.M.; SOUZA FILHO, H.M. Tecnologia de gestão e agricultura familiar. In: SOUZA FILHO, H.M.; BATALHA, M.O. (orgs.). Gestão integrada da agricultura familiar. São Carlos: EduFSCar, 2005.

FEARNSIDE, P.M. Desmatamento na Amazônia brasileira: história, índices e conseqüências. Megadiversidade, Manaus, vol.1, n 1, 15 p. Jul. 2005. Disponível em:

http://philip.inpa.gov.br/publ_livres/2005/Desmatamento\%20historiaMegadiversidade .pdf > Acesso em: 15 mai. 2017.

FRAGOSO, R. O.; CARPANEZZI, A. A.; KOEHLER, H. S.; RIBAS, K. C. Barreiras ao Estabelecimento da Regeneração Natural em Áreas de Pastagens Abandonadas. Ciência Florestal, Santa Maria, v. 27, n. 4, p. 1451-1464, out.-dez., 2017. Disponível em: < http://www.redalyc.org/pdf/534/53453782030.pdf> Acesso em: 17 jun. 2018.

GREENPEACE. Amazônia. São Paulo, 2017. Disponível em: <http://www.greenpeace.org/brasil/pt/O-que-fazemos/Amazonia/>. Acesso em: 15 mai. 2017.

GUIMARÃES, B. B.; GUIMARÃES, R. B.; LEAL A. C. Conceito de Área de Preservação Permanente e sua Aplicação na Bacia Hidrográfica do Córrego São Pedro - Anhumas, São Paulo. Boletim Campineiro de Geografia, v. 5, n. 1, 2015. Disponível em: < http://agbcampinas.com.br/bcg/index.php/boletimcampineiro/article/view/192/127>. Acesso em: 25 jun 2018.

IBGE - Instituto Brasileiro de Geografia e Estatística . Cidades. 2016.

NORA, G.D.; NETTO L.R.G. Características Políticas e Naturais dos Recursos Hídricos no Estado de Mato Grosso. Geonorte, Edição Especial, V.3, N.4, p. 692- 
702, 2012. Disponível em: < http://periodicos.ufam.edu.br/revistageonorte/article/view/1980> Acesso em: 02 mai. 2018.

PARADELLA, W. R.; CECARELLI, I. C. F.; LUIZ, S.; OLIVEIRA, C. G.; OKIDA, R. Geração de Carta Topográfica com Estéreo-pares Fine do RADARSAT-1 e Dados ETM+ LANDSAT 7 em Ambiente de Relevo Montanhoso na Região Amazônica (Serra dos Carajás, Pará). Revista Brasileira de Geociências. Ano 4. № 1. 17-29. 2003. Disponível em: < http://www.Isie.unb.br/rbg/index.php/rbg/article/view/17/15> Acesso em: 15 mai. 2017

PONS, N. A. D.; PEREIRA, I. Z. Estudo da Qualidade Ambiental de APP de Nascentes da Bacia do Ribeirão José Pereira, com o Auxílio do Geoprocessamento. Revista Brasileira de Energias Renováveis, v. 7, n. 1, p. 120-132. 2018. Disponível em: < https://revistas.ufpr.br/rber/article/view/57973/34873>. Acesso em: 25 jun 2018.

ROMERO, E. C. O.; LEITE, V. L. M. Terras indígenas: usufruto exclusivo e proteção do meio ambiente. Revista TELLUS. N 18, p. 139-160, Campo Grande, 2014. Disponível em: http://tellus.ucdb.br/projetos/tellus/index.php/tellus/article/view/203> Acesso em: 01 jun. 2018

SILVA, M. D. S.; VALE, V. S.; VAZ, A. C. R.; Efeito de Borda em Fragmentos Florestais Ocorrentes em Clima Sazonal. In: Congresso de Ensino Pesquisa e Extensão da UEG (CEPE), v. 4, 2017, Ipameri. Anais... ,ISSN 2447-8687. Disponível em: < http://www.anais.ueg.br/index.php/cepe/article/view/10643/7865> Acesso em: 11 jun. 2018

SOARES, R. B.; SOARES, C. B. S. S.; COSTA, J. A. L.; COSTA, S. S.; SOARES, R. Aplicação de técnica de fusão em imagens Landsat 8/ OLI. In: XVII Simpósio Brasileiro de Sensoriamento Remoto, 2015, João Pessoa. Anais... INPE, p. 48364843.

em: <http://marte2.sid.inpe.br/col/sid.inpe.br/marte2/2015/06.15.15.46.48/doc/p0944.pdf> Acesso em: 11 jun. 2018

SOARES-FILHO, B.S.; CERQUEIRA, G.C.; GARCIA, A.R.; NEPSTAD, D.C. Cenários de desmatamento para a Amazônia. Dossiê Amazônia brasileira II, Estud. av. vol.19 no.54 São Paulo. 2005. Disponível em: < http://www.scielo.br/scielo.php?pid=S010340142005000200008\&script=sci_arttext> Acesso em: 12 mai. 2018.

WOLLMANN, L. M.; BASTOS, L. C. Novo código florestal e reserva legal em propriedades rurais do município de Porto Alegre/RS. Ciência Rural, Santa Maria, 2015. ISSN 0103-8478. Disponível em: http://www.scielo.br/pdf/cr/2014nahead/01038478-cr-00-00-cr20140432.pdf>. Acesso em: 3 jun 2018. 